\title{
Opinion
}

\section{Wound Care and Healthcare}

\author{
Lydia A. Corum, RN, MSN, CWCN*
}

Wound Care Program Director

"Corresponding author

Lydia A. Corum, RN, MSN, CWCN

Wound Care Program Director; E-mail: lydia.meyers317@gmail.com

Article information

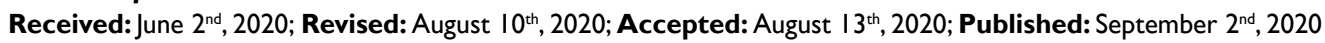

\section{Cite this article}

Corum LA. Wound care and healthcare. Emerg Med Open J. 2020; 6(I): I-2. doi: I0. I7। 140/EMOJ-6-I54

\begin{abstract}
A case was reported in the wake of stepping on a sharp nail in 1 a board where the patient was given a Tetanus shot and sent home with advice to apply triple antibiotic cream twice a day and wrapping the injury with gauze along with oral antibiotics. The patient was suggested to soak his foot in Dakin's Solution..
\end{abstract}

The patient returns after 2 weeks to the emergency room (ER), limping and not bearing weight on the injured foot. The patient states that he had been doing the dressing changes and noted the area was becoming odorous. He was unable to walk on the foot or get his boots on for work. The foot was swollen and odorous with an enormous amount of discharge from the wound. The foot was soaked in Dakins by the staff. The surgeon was called and the ulcer was examined. Upon instruction, an magnetic resonance imaging (MRI), culture, labs, intravenous (IV) antibiotics, and admission, with surgery scheduled for in AM. The patient was found to be diabetic. Aware of this the surgeon and the internist assigned to the case, continue the work on to include a cardiologist and vascular surgeon. . Amputation was performed which led to a major change in the patient's life. The patient failed to return to his previous occupation and could not support his family.

Prior to the coronavirus disease 2019 (COVID-19) virus, admission to hospital for wound care patients takes place every day. This practice changed drastically after COVID-19 despite the focus of the hospital to take care of patients that needed care. The COVID-19 virus caused an increased number of deaths, severe health conditions, and many were at the risk of acquiring the COVID-19 virus. Many wound care patients lacked care. The hospitals were confused about choosing to close the wound clinics due to the lack of personnel resources and lack of patient visits. ${ }^{1}$ The wound care community could not allow this situation to continue. The fear that wound patients would face an increase in infections, decrease in healing, or increase in amputation rates. The community looked for ways to change the system and wound clinics reopened to a new world. ${ }^{2}$ There still remain many problems for the future of wound care. This paper highlights what has caused the problems, how the new normal will help the present, and what needs to happen in the future.

Health care has been facing challenges for many years. From the time of the depression become known to the days when it was found a need for Medicaid. This country has seen a need to provide healthcare for all. Our system is not a healthy one, compared to care in other countries. We are numbered with the cost of healthcare per person in the company with the quality of care. ${ }^{3}$ The COVID-19 virus only has brought to light many problems and the ways to continue to move this country forward. ${ }^{4}$ Changes are usually difficult. Many in the healthcare community are less appreciative of this change. The COVID-19 virus has started the change and a strong leader needs to push it forward. Leaders in the healthcare system will have the vision to move the system forward. Seeing the big picture, bringing those important people with them, and pushing the system forward. ${ }^{3}$

Some leaders are pushing for universal care, as used in other countries. This system is based on the population working as ours is. This can be a good system or not. The answer to our problems is not to use others, but to refine our system. To just throw away and scrap does not make sense. There are many times and many cases of abuse in the system. Changing the abuses will help improve care and push forward more funds. ${ }^{2}$

As healthcare continues to face a major crisis, the wound care community faces its first drastic change. When the epidemic and lockdown hit the US, wound care was pushed to being a non -essential part of healthcare. This increased the hardship of many patients with wounds and ulcers as they cannot find a resource for healing. Seeing life as being locked in a house suffering long days of being unable to be around others. The odor, pain, itch, leakage, and increased chance of infection, have locked these patients into their home. ${ }^{5}$ The closing of wound clinics would be devastating 
to the wound care community. Many patients go through a wound clinic in a single day, and that includes the use of hyperbaric oxygen therapy (HBOT). Many clinics are healing wounds of the patients. To have the ability to access to the clinics is drastically important. ${ }^{6}$ The ER would do their best to serve their patients that relieve future visits and helps to assure the patients are getting the treatment that they need. This will reduce hospital costs and financial costs.

The new normal with wound care was static for many years. The government was more focused on the other diagnoses. However, there was no focus on what was happening in wound care. Wound Clinics are needed to help with patient retention, increased patient satisfaction, and increased outpatient revenue. What COVID- 19 has changed to become the new normal is Telemedicine, decreased visits in the wound clinic, and different rules for home health care. Telemedicine is to help assess wounds without making visits. ${ }^{7}$ Allowing patients to be admitted into home healthcare, even if the patient is not homebound. More patients are able to have oversight of the wound progression and if the patient needs to be seen before the next appointment. The decrease in the number of clinic visits and how patients are seen in the clinic allows more time between visits, fewer patients seen in the clinic, and short wait times. ${ }^{6}$ This would increase the need for more wound clinics and increase the need for more rooms. There is a need for hand sanitizer, with masks for all entering the clinic, how patients are seen, what is available in the clinic, and how staff enters the room. The changes happening is only the beginning of what needs to happen with the coming future. ${ }^{8}$

The focus of future wound care will need to be on patient satisfaction, quality, and financial stewardship. This new world is being monitored by central monitoring system (CMS) and the audits being performed. ${ }^{9}$ With the present situation, many hospitals are looking at how to handle wound care patients, surgical debridements, and keeping patients from being admitted to the hospital. ${ }^{6}$ The concern of many wound care clinicians is to reduce the risk of infections. Many are scheduling surgical debridements as outpatient, and outpatient surgical centers. Those patients admitted with wounds and ulcers are seen by a team of clinicians. This minimizes the chances of exposure to bacteria and viruses. Rules of home healthcare are being lifted so that many patients, who are not homebound can be helped by the nurses coming to assess. Telemedicine is being used to interact with those wound clinicians who have the expertise and understanding from the homes of patients with wounds. This could be the future of wound care or many may come up with better ideas with time. ${ }^{6}$
The future of wound care depends on many factors now and in the future. The treatment of the new viruses are not over. Also, there is a need to monitor people with ulcers and wounds. There will be better monitoring and care as time goes on. These need to be thoughtful, long-term with proper planning in the future. The plan to help with controlling financial stewardship will be the main focus. The focus of continuing quality of care, patient satisfaction, and financial stewardship. Evidence-based care needs to be the focus and wound care clinicians must continue to seek education, seminars, and conferences. More ideas should be acquired as well as new lessons. One should never stop listening, learning and becoming better.

\section{REFERENCES |}

1. Lazarevski L. Wound Care During COVID-19. woundsource Web site. www.woundsource.com/blog/wound-care-during-covid-19. Accessed June 1, 2020.

2. Harriet J. Considerations and recommendations regarding the COVID-19 virus for wound centers. Today's Wound Clinic. 2020; 14(4): 18-21.

3. Jane G. Practical Guide to Qualitative Healthcare. Indiana, USA: Author Solutions; 2015.

4. Kurani N, McDermott D. How Does the U.S. Healthcare System Compared to Other Countries?. ealthsystemtracker Web site. https://www.healthsystemtracker.org/chart-collection/quality-us-healthcare-system-compare-countries/. Accessed June 1, 2020.

5. Sharon B, Ayello EA. Wound Care Essentials: Practice Principles. South Holland, Netherlands: Wolters Kluwer; 2016.

6. Samuel NT, Collins N. Avoiding unintended consequences for the complex wound patient in the fight against COVID-19. Today's Wound Clinic. 2020; 14(4): 26-29.

7. Rogers LC, Armstrong DG, Capotorto J, Fife CE, Garcia JR, Gelly H, et al. Wound center without walls: The new model of providing care during the COVID-19 pandemic. Wounds. 2020; 32 (7).

8. Workman WT. A closer look at hyperbaric safety and training. Today's Wound Clinic. 2020; 14(5): 22-23.

9. Knicole E. Update on medicare/medicaid audits in the wake of COVID-19. Today's Wound Clinic. 2020; 14(5): 24-27. 